\title{
THE MICROCOMPUTER CONVERTER OF THE TELEX SIGNAL
}

This paper deals with a structure and a description of the microcomputer converter of the telex signal (MCTS) that we developed for the Slovak Telecom. The microcomputer converter was developed within the International contract between Hungary Telecommunication Association Matav, Slovak Telecom in Bratislava, and Department of Telecommunications at the University of Zilina. We made the following tasks: design, debugging and testing of the resident program of the converter. After evaluation of the prototype by the company Matav 150 pieces of the converters, were manufactured and then successfully implemented in the TELEX exchange in Slovak Telecom in Bratislava for continuous operation.

\section{An implementation of the MCTS modules into the system of the telex signalling}

The microcomputer converter of telex signal emulates the telex subscriber signalling. The module consists of two identical single-chip microcomputers and supporting peripheries, which enable their implementation into the system of the telex signalling. Two subscribers of the telex operation are connected to one module, which consists of two converters. The system enables to connect up to 150 subscribers of the telex network. The modules MCTS realize the conversion from the signalling of the telex terminals that are located in Hungary, to the signalling of the telex exchange AXB20 situated in Bratislava. The conversion of the signalling is realized in the time and character domain. MCTS manages the signalling for the calling subscribers (the outgoing direction) and the called subscribers (the incoming direction) in different ways. It also manages the signalling of successful national and international calls as well as unsuccessful calls. It handles timing and ordering of the character sequences in both directions: "sub-

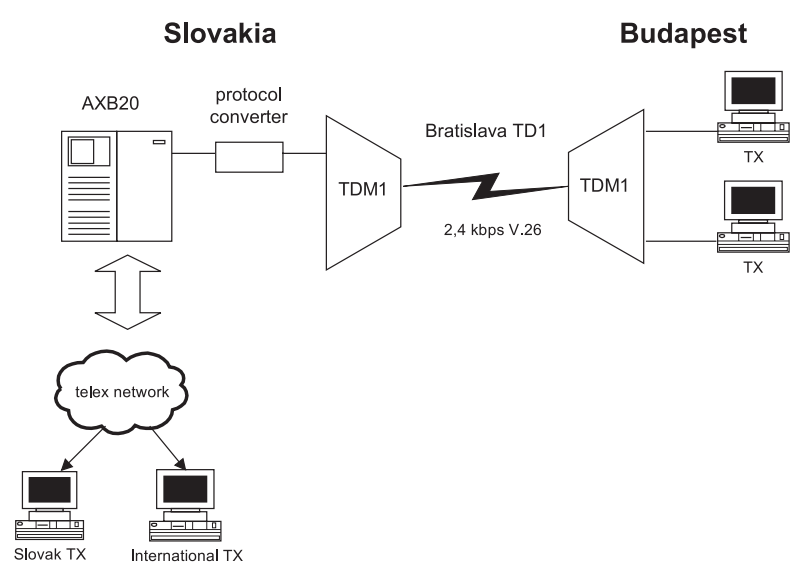

Fig. 1 Telex transmission system with the converter scriber - telex exchange" and "telex exchange - subscriber" for all types of the calls.

The telex exchange AXB20, the transmission system of the telex signals between Budapest and ST Bratislava and the microcomputer converter of the telex signalling are shown in Fig. 1. It is seen from Figure 1 that through the microcomputer converter telex terminals in Hungary are connected to the telex exchange AXB20, by which they are controlled.

\section{Architecture of the MCTS module}

An architecture of the microcomputer converter of the telex signals is based on the single-chip microcomputer of 8051 family and its supporting peripheries (See Fig. 2). The storage space consists of the fixed program memory EPROM with the total capacity of $16 \mathrm{kB}$ and the data memory of $2 \mathrm{kB}$. The circuits of the system interface are optically isolated. The optical isolation interface block OII consists of isolation optoelements as well as circuits of the combination logic and the power elements. They form the electrical interface for connecting MCTS to the transmission system of the telex exchange AXB20 and the interface TDM1.

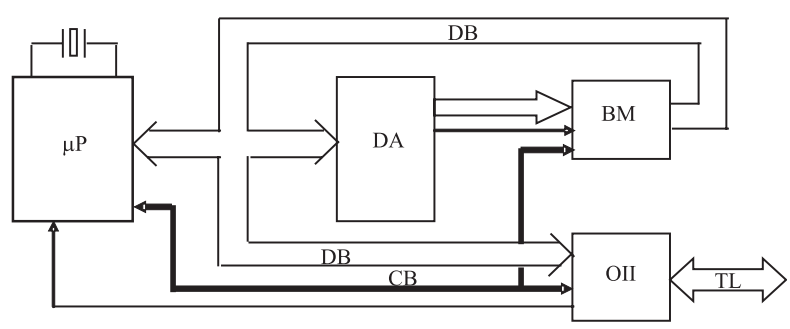

Legend: $\mu \mathrm{P}-$ the single-chip microcomputer, $\mathrm{DA}-$ the decoder of the address, $\mathrm{BM}$ - the block of the memories (RAM, EPROM), OII - the optical isolated interface, $\mathrm{DB}-$ the data bus, $\mathrm{CB}-$ the control bus, $\mathrm{TL}-$ the telex line

Fig. 2 The microcomputer converter of telex signal

\footnotetext{
* Vladimír Hottmar, Michal Kuba

Department of Telecommunications, Faculty of Electrical Engineering, University of Žilina, Žilina, Slovakia,

E-mail: vladimir.hottmar@fel.utc.sk, michal.kuba@fel.utc.sk
} 


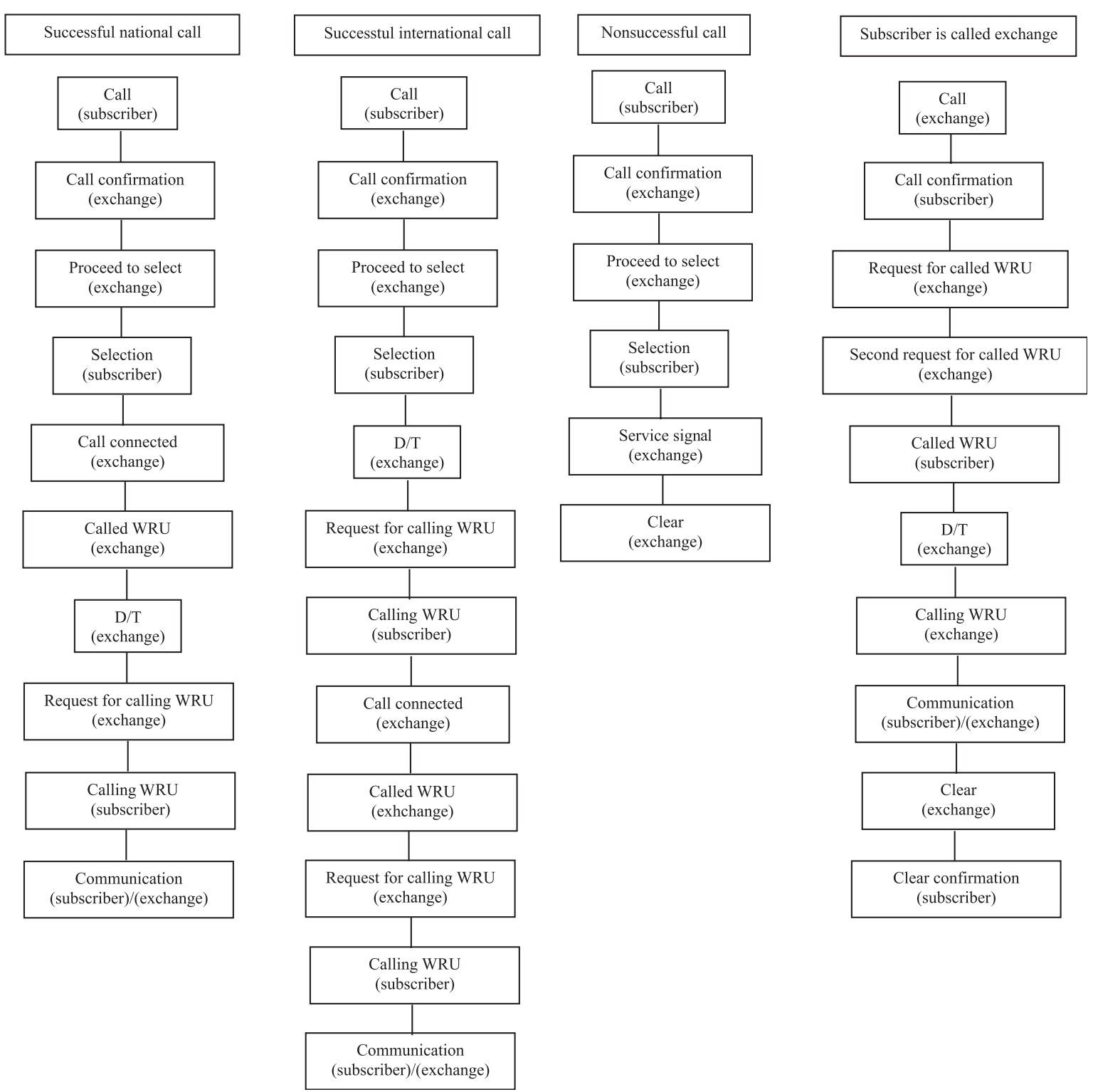

Fig. 3 The signalling procedures preformed by the converter

\section{Converter activity description}

The microcomputer converter controls the telex signalling and the converter's activity is initialized by calling the subscriber, or by the exchange when the subscriber is called. The converter performs several types of signalling (See Figure 3 ) in dependence on the type of call as follows:

a) The successful national call, when the subscriber is calling. It represents the outgoing direction.

b) The successful international call, when the subscriber is calling. It represents the outgoing direction.

c) The unsuccessful call of the subscriber. The connection is not established and the exchange sends the terminal an appropriate service signal to $\log$ off the connection. d) The subscriber is called by the exchange for the national and international calls

\section{Conclusion}

Hungary Telecommunication Association Matav asked the Slovak Telecom to modify their telex signal (TS). For this purpose we developed the microcomputer converter of the telex signal (MCTS). The converter was developed within the International contract between Hungary Telecommunication Association Matav, Slovak Telecom in Bratislava, and the Department of Telecommunications of the University of Zilina. After evaluation of the prototype by the company Matav, 150 pieces of the converters 


\section{References:}

[1] Technical specification, requirements based on the Hungarian attributes.

[2] Transmission system SZT 2400.

[3] Test minutes of ST telex model, Matav, Budapest, 28 November 2001. 